\title{
"AGRUPADOS ES LA ÚNICA FORMA". LA EXPERIENCIA SOLIDARIA Y AUTÓNOMA DE LA COOPERATIVA CHACAY MAMIL
}

\section{"Grouped is the only WAy". The SOlidarity and autOnOMOUS EXPERIENCE OF THE CHACAY MAMIL COOPERATIVE}

Fecha recepción: 4 de septiembre de 2020 / fecha aceptación: 29 de diciembre de 2020

\author{
Natalia Luque ${ }^{1}$, Hugo Bottaro y y Graciela Preda ${ }^{3}$
}

Cómo citar este artículo:

Luque, N., Bottaro, H. y Preda, G. (2020). "Agrupados es la única forma". La experiencia solidaria y autónoma de la cooperativa Chacay Mamil. Revista Pensamiento y Acción Interdisciplinaria, 6(2), 50-69. http://doi.org/10.29035/pai.6.2.50

\section{Resumen}

Son escasos los antecedentes de estudios sobre cooperativismo agrario en Patagonia, y más aún en la región sur. Es por ello que el presente trabajo se propone analizar la conformación y trayectoria de la cooperativa "Chacay Mamil" - ubicada en el departamento Tehuelches en la provincia de Chubut, Argentina-, como una estrategia de acción colectiva de un grupo de pequeños ganaderos. La cooperativa inició sus actividades en el año 2007 y en la actualidad participan activamente 35 asociados. La metodología utilizada en el análisis y desarrollo de este trabajo es de carácter cualitativo, y el instrumento para la recolección de datos fue la entrevista en profundidad, realizada a diferentes socios, a quienes ocuparon y ocupan cargos directivos y a técnicos que fueron parte de la gestión inicial. Asimismo, se analizaron fuentes documentales -libro de actas, memorias e informes de proyectos-. Del análisis de la trayectoria de la Cooperativa se desprende la importancia de los saberes previos y la experiencia acumulada de sus asociados a lo largo del proceso, como así también el grado de independencia y autogestión alcanzada. También queda en evidencia que la puesta en práctica de los valores cooperativos les permitió dar respuesta a necesidades históricas. El trabajo posibilita además, reflexionar acerca del rol de las políticas públicas en el apoyo a iniciativas socio-organizativas en el ámbito rural.

Palabras clave: Agricultura familiar, Cooperativismo, Estrategia colectivas, Patagonia, Políticas públicas

\footnotetext{
1 Licenciada en Geografía. Instituto Nacional de Tecnología Agropecuaria. Esquel. Argentina. luque.natalia@inta.gob.ar 2 Ingeniero Agrónomo. MSC Recursos Naturales. Instituto Nacional de Tecnología Agropecuaria-Facultad de Ciencias Económicas Universidad Nacional de la Patagonia. Esquel, Argentina. bottaro.hugo@inta.gob.ar

3 Argentina. Investigadora. Doctora en Estudios Sociales Agrarios. Instituto Nacional de Tecnología Agropecuaria. Neuquén, Argentina. preda.graciela@inta.gob.ar
} 


\begin{abstract}
There are few studies on the history of agricultural cooperatives in Patagonia, and even more in the southern region. That is why the present work aims to analyze the conformation and trajectory of the cooperative "Chacay Mamil" -located in the department of Tehuelches in the province of Chubut, Argentina-, as a strategy of collective action of a group of small farmers. The cooperative began its activities in 2007 and currently 35 associates actively participate. The methodology used in the analysis and development of this work is of a qualitative nature, and the instrument for data collection was the in-depth interview, carried out with different partners, those who held and hold management positions and technicians who were part of the management initial. Likewise, documentary sources- minute book, memoirs and project reports- were analyzed. From the analysis of the trajectory of the Cooperative, the importance of previous knowledge and the accumulated experience of its associates throughout the process, as well as the degree of independence and self-management achieved, can be seen. It is also clear that the implementation of cooperative values allowed them to respond to historical needs. The work also makes it possible to reflect on the role of public policies in supporting socio-organizational initiatives in rural areas.
\end{abstract}

Keywords: Family agriculture, Cooperativism, Collective strategy, Patagonia, Public politics.

\title{
Introducción
}

Pensar la permanencia de la pequeña producción agropecuaria en el actual contexto de capitalismo avanzado, involucra necesariamente el análisis de las distintas estrategias que desarrolla y su relación con las acciones de los agentes con los que interactúan en el marco de las políticas públicas implementadas.

La historia de la región patagónica y la organización de su territorio, estuvo signada por la campaña militar que se dio entre los años 1878 y 1885 con el propósito de incorporar ese espacio geográfico al esquema productivo del país, y afianzar así la soberanía nacional (Barsky \& Gelman, 2006). Una vez en manos del Estado, grandes extensiones de tierra fueron repartidas a militares y colonos estancieros-como forma de pago- a costa del aniquilamiento y marginación de los pueblos originarios (Maggiori, 2010). Ese modelo concentrador-mucha tierra en pocas manos- generó una estructura agraria que se sostiene hasta la actualidad, donde quedaron desplazadas las comunidades ancestrales a las "estepas desérticas o valles salitrosos" (Maggiori, 2010, p. 60), impidiendo de este modo un desarrollo territorial equilibrado.

Pero los sujetos sociales tienen capacidad para implementar estrategias que les posibiliten mejorar sus condiciones de vida, ya que según Bourdieu se valen de la experiencia acumulada en su historia productiva para idear formas de afrontar los problemas aún en situaciones de extrema coerción, "[...] producto de la historia, el habitus produce prácticas, individuales y colectivas, produce, pues, historia conforme a los principios engendrados por la historia" (1991, p. 94). Y son las formas organizativas, como estrategia colectiva, las que pueden brindar las herramientas que permitan enfrentar tanto los problemas de escasez de recursos 
"Agrupados es la única forma". La experiencia solidaria y autónoma de la cooperativa Chacay Mamil por Natalia Luque, Hugo Bottaro y Graciela Preda

como también crear procesos de aprendizaje y generar "estrategias de negociación y confrontación con otros actores e instituciones" (Giarraca, 2017, p. 218).

En el año 2002, en el centro oeste de la provincia de Chubut un grupo de pequeños productores ganaderos -muchos de ellos pertenecientes a la etnia mapuche/tehuelche- comenzaron a organizarse en pos de la conformación de una cooperativa, la Chacay Mamil, en un contexto de emergencia de políticas públicas que alentaban iniciativas de ese tipo.

El presente artículo se propone analizar la génesis y trayectoria de esta cooperativa, y conocer -a partir del relato de los propios protagonistas- el "conjunto de prácticas" (Bourdieu, 1988, p. 122) realizadas en el marco de esta estrategia colectiva, en pos de preservar sus posiciones en el espacio productivo de la región.

\section{Metodología}

Entendiendo que "el mundo social es el producto de actos de construcción que los agentes operan en cada momento" (Bourdieu, et al. 2002, p.1), nos proponemos abordar las formas en que se reproduce la vida social de los pequeños productores ganaderos y la dinámica de los agentes o grupos de agentes que coexisten en el mismo espacio social. Para ello se priorizó un enfoque de análisis cualitativo, con el propósito de prestar atención a los detalles, sucesos, eventos e interacciones (Sampieri, 2010).

Como la característica del muestreo cualitativo es su conducción intencional en la búsqueda de los casos que propicien información significativa (Patton en Sandoval Casilimas, 2002), se realizaron entrevistas semiestructuradas a nueve socios, que por su experiencia pudieron dar testimonio de la trayectoria de la cooperativa. Se utilizó ese instrumento debido a que contiene características propias de la entrevista estructurada, en el sentido de la preparación anticipada de una guía de pautas, pero a la vez contempla preguntas abiertas que permiten generar información en profundidad, proporcionando un rico material de análisis (Schwartz y Jacobs, 1984).

También se entrevistó a un técnico a un técnico de la Subsecretaria de Agricultura Familiar (SSAF), quien acompañó el proceso de conformación de la cooperativa. Por otra parte, se analizaron fuentes documentales y material bibliográfico que posibilitaron caracterizar el área de estudio.

Las entrevistas se realizaron durante los años 2017 a 2019, dado que este trabajo se desprende de una investigación mayor que aborda las transformaciones socio-productivas en el departamento Tehuelches en las últimas décadas. 


\section{Marco referencial}

Resulta apropiado hacer mención a la situación contextual en torno a la cooperativa Chacay Mamil, para así poder comprender los orígenes de su conformación, los objetivos iniciales, el desarrollo de sus actividades y quiénes-y porqué- integran este espacio.

En primer lugar, se realiza una breve reseña histórica de la ocupación de la región patagónica, especialmente en el departamento Tehuelches, y por otra parte, se enumeran las políticas públicas vinculadas al desarrollo de la agricultura familiar.

\section{Incorporación del territorio al Estado argentino}

El departamento Tehuelches debe su nombre a los habitantes nativos del lugar, "quienes definieron en sus largas marchas esas antiguas veredas que bordean los ríos y que siguieron los primeros exploradores que se internaron en el territorio. Estas veredas se transformaron con el tiempo en huellas de carretas, originando con el tiempo las actuales rutas" (Maggiori, 2003: 10). Como todo territorio está condicionado por una impronta social y cultural que se remonta en el tiempo, y por una geografía y una historia de contrastes.

En el periodo que sobrevino a la campaña militar desarrollada entre 1878 y 1885 "se logró la rendición total de los últimos caciques patagónicos como Sayhueque" (Bandieri, 2005: 145) y se reconfiguró el territorio de la denominada Patagonia. El éxito de la conquista militar sobre los espacios indígenas derivó en la afirmación definitiva de la soberanía del Estado Nacional sobre estas regiones (Bandieri, 2005). Asimismo, Maggiori relata que las tierras de los pueblos originarios apropiadas por el Estado se dividieron y se transfirieron en propiedad a nuevos dueños "[...] a medida que se avanzaba en la expansión de la frontera y se tomaba posesión de las tierras, comenzaban la demarcación de mensuras en lotes de cuatro leguas cuadradas (10.000 ha). Se reservarían terrenos para el asentamiento de nuevos pueblos, y se producirían los primeros antecedentes de reservas para el establecimiento de los indios" (2003: 30). Mientras que, por una parte, y mediante la Ley de Premios Militares se adjudicaban tierras a jefes, oficiales y tropas que habían participado en la expedición; por otra, y a través de la Ley de Hogar, tuvieron su origen las Reservas Indígenas (Maggiori, 2003).

Habiendo transcurrido más de una década se procedió a la localización definitiva del cacique Sayhueque y su tribu, a través de la entrega de pequeñas superficies de tierra en zonas marginales. "[...] en una zona de Chubut denominada Las Salinas, en el departamento Tehuelches. Allí ocupó Sayhueque, con 222 miembros de su tribu, terrenos en la Colonia Pastoril General San Martín" (Bandieri, 2005. P. 148). 
"Agrupados es la única forma". La experiencia solidaria y autónoma de la cooperativa Chacay Mamil por Natalia Luque, Hugo Bottaro y Graciela Preda

Tal como afirma la historiadora, en un informe de tierras de 1930 se daba a conocer el lamentable estado de miseria en que vivía la comunidad, "[...] seguían haciendo gestiones para conseguir los títulos definitivos de sus propiedades aludiendo a su condición de descendientes de un cacique aliado de los blancos" (2005, p.149). Para ese entonces Sayhueque había fallecido (1903), y sin su presencia la comunidad había adquirido deudas y perdido tierras que se encontraban en arrendamiento, las cuales pasaron a una firma comercial dedicada al acopio de frutos del país y ramos generales. Como bien lo sintetiza Maggiori (2003, p. 149), "la conquista del desierto no había terminado para ellos, al sable y al Remington, lo sustituyen papeles y abogados".

En este sentido, la región no ha quedado exenta de las prácticas habituales de algunos comercios de ramos generales en su vínculo con los pequeños productores agropecuarios: el endeudamiento a partir de la adquisición de bienes de consumo e insumos sobrevaluados contra el compromiso de entrega futura de productos ganaderos subvaluados. Esta práctica, sostenida en el tiempo, derivó muchas veces en la ejecución de las propiedades de pequeños productores, generalmente pertenecientes a los pueblos originarios. Cabe mencionar que ese despojo resulta doblemente traumático porque la tierra no es sólo un medio de producción, sino el ámbito donde ellos viven y con el que guardan un vínculo particular donde se arraigan sus pautas culturales.

A diferencia de lo ocurrido en otros lugares de la provincia, estos pobladores no llegaron a conformarse en comunidad ni a constituir una "reserva". Las pequeñas fracciones de campo que ocupan quedaron diseminadas entre estancias pertenecientes a inmigrantes europeos o sociedades comerciales (Maggiori, 2003).

Muchos de los integrantes de la Cooperativa Chacay Mamil son descendientes de esos pobladores originarios, y en sus relatos actuales hay una reivindicación de su historia, tradición y cultura.

\section{Políticas públicas implementadas en las últimas dos décadas}

Como consecuencia del conflicto agrario ocurrido en 2008, el Estado Nacional comenzó a desarrollar políticas que "posibilitaron un mayor grado de inserción institucional y de visibilidad de la agricultura familiar, junto a cambios en los objetivos e instrumentos de los programas destinados a la misma" (Fernández, 2018, p. 219). Recreándose así la relación entre el Estado y la Agricultura Familiar que fue ganando protagonismo en la agenda pública vinculada al desarrollo rural, a la vez que se incrementó su visibilización y valoración en cuanto al rol que cumple como proveedora de alimentos para el mercado interno, y no como meros destinatarios de políticas sociales de asistencia. 
Entre las políticas más salientes podemos mencionar la creación de la Subsecretaría de Desarrollo Rural y Agricultura Familiar de la Nación (SsDRyAF) en el año 2008, elevándose al rango de Secretaría en setiembre de 2009 (Nogueira, et al., 2017). Asimismo, y a partir del convenio entre el Ministerio de Agricultura, Ganadería y Pesca y el Ministerio de Desarrollo Social de la Nación en el 2009, los pequeños productores accedieron al beneficio del Monotributo Social Agropecuario (Nogueira, et al. 2017), permitiendo que buena parte del sector informal accediera a obra social, jubilación y posibilidad de formalizar sus operaciones a través de la facturación. También se creó el Registro Nacional de la Agricultura Familiar (RENAF) y se vio fortalecido el Foro Nacional de la Agricultura Familiar (FONAF), creado en el año 2006.

En este marco, el Instituto Nacional de Tecnología Agropecuaria (INTA) fortaleció el Programa Federal de Desarrollo (PROFEDER) y reformuló otros que venía implementando para el sector, como el ProHuerta, que dejó de tener foco en el autoabastecimiento alimentario familiar y pasó a ser promotor de pequeños emprendimientos productivos y comerciales para abastecimiento local (huertas comunitarias, ferias, mercados, entre otros). Posteriormente, en el año 2014 se implementó el Programa Cambio Rural II, el cual reconoció dentro de su población beneficiaria al sector de la Agricultura Familiar en transición; y en el mismo año se sancionó la Ley 27.118 de la Agricultura Familiar, aunque aún no ha sido reglamentada.

Las políticas mencionadas tuvieron su impacto en Chubut, donde se constituyó el Foro para la Agricultura Familiar y se fortalecieron las organizaciones de pequeños productores.

Por otra parte, en la región se agudizaron una serie de cambios de índole ambiental que impactaron en el desarrollo productivo, asociados a la confluencia de procesos físico-naturales y la sobrecarga del suelo, que derivaron en la pérdida de productividad de las tierras y la degradación de los ecosistemas (Murgida \& Gentile, 2014); situación que fue descripta específicamente para esta zona a partir de estimaciones, utilizando como indicador el NDVI ${ }^{4}$ (Gaitán et al., 2015).

Frente a la convivencia de los problemas ambientales y la crítica situación de la ganadería ovina, Murgida y Gentile (2014, p. 15) señalan que "lentamente el Estado comenzó a abordar formalmente la complejidad del sistema productivo. Fue con la Ley $N^{\circ}$ 25.422/2003 que se propiciaron programas para la recuperación de la ganadería ovina a través de proyectos y líneas de crédito directo o aportes no reintegrables a productores organizados". Ejarque (2014, p. 269) argumenta que la ley 25422/01-Régimen para la recuperación de la ganadería ovina -coloquialmente conocida como "ley ovina"- su reglamentación en el Decreto y su prórroga "constituyen un hito [...] ya que es la primera que engloba a todo el sector en un solo marco legal y que se mantiene hasta la actualidad vigente". La

4 NDVI (Normalized Difference Vegetation Index). 
"Agrupados es la única forma". La experiencia solidaria y autónoma de la cooperativa Chacay Mamil por Natalia Luque, Hugo Bottaro y Graciela Preda

misma permanece vigente dado que se sancionó la prórroga en el año 2011 por considerar que la crisis del sector ovino no había sido superada.

Posteriormente, el Estado provincial (con el objetivo de fortalecer la medida implementada a nivel nacional) declaró la Emergencia Agropecuaria en el año 2007, iniciándose un proceso de construcción de espacios en torno a las iniciativas de la Subsecretaría de Agricultura Familiar de la Nación. "Esto permitió dar a conocer las necesidades de las cooperativas, comunidades y familias, para recibir aportes reintegrables y no reintegrables, que les permitieran realizar (en cada comunidad o cooperativa), obras para captación, extracción, almacenaje y distribución de agua, mejoramiento de forraje, y sistemas de comercialización directa" (Murgida \& Gentile, 2014, p.16). En el mismo año, el Ministerio de Industria, Agricultura y Ganadería de la Provincia (MIAG) con el propósito de apoyar al sector ganadero estableció el Plan Ovino, por medio del cual se definieron ejes estratégicos de trabajo fortaleciendo el "PROLANA como sistema de mejora de la calidad de presentación y las oportunidades de venta de la lana" (Ejarque, 2014, p. 270).

A nivel local, en el año 2012 se conformó la Mesa de Desarrollo del Departamento Tehuelches. La misma es parte de un proceso que se extiende a buena parte del área rural de la provincia de Chubut, y se trata de un espacio integrado por "representantes de municipios, organismos públicos nacionales y provinciales, organizaciones de productores y en algunos casos de comunidades de pueblos nativos. La conformación de este tipo de instancias se ha intensificado a pesar de no existir aparentemente una política clara desde el estado para su promoción" (Li, Bottaro, 2010), y su legitimidad está dada por el propio reconocimiento de sus integrantes.

\section{Resultado y discusión}

Según Lattuada y Renold, el asociativismo en el sector agropecuario cobró importancia a partir de la década del noventa, debido a que, en ese contexto de desregulación, apertura económica y concentración productiva, los sectores más vulnerables de la estructura agraria -pequeños y medianos productoresencontraron en las propuestas asociativas "alternativas para lograr escala, valor agregado y seguridad en el mercado" (2004, p. 9).

Los estudios sobre el cooperativismo en las ciencias sociales generalmente se abordaron desde las perspectivas económica, jurídica y sociológica, y es precisamente desde esta última donde se inscribe el presente trabajo. Giarraca afirma que el interés radica en que son algo más que una empresa, "son formas que encuentra la gente para resolver necesidades de manera conjunta; en tal sentido, las acciones colectivas y la organización son complementarias, son dos facetas indisociables del mismo problema que remiten a la construcción de los actores o agentes sociales" (2017, p. 201). 
De acuerdo a la información disponible, la trayectoria del cooperativismo agrario en la provincia de Chubut se remonta a mediados del siglo XX y no ha tenido un gran desarrollo: en 1951 se registraron cuatro cooperativas, siete en el año 1966 y dos en 1994 (Lattuada \& Renold, 2004); y para el año 2006, de acuerdo a datos tomados del Instituto Nacional de Asociativismo y Economía Social (INAES), el total de cooperativas agropecuarias en la provincia era de dieciséis (Ressel \& Silva, 2008). Asimismo, los antecedentes de estudios sobre cooperativismo agrario en la provincia son escasos.

El proceso de disminución de explotaciones ocurrido en los últimos años a escala nacional también se visualizó en el departamento Tehuelches, donde se registró una caída del 7\% de las explotaciones agropecuarias (EAPs) entre los Censos Nacionales Agropecuarios (CNA) (INDEC, 2002 y 2008), coincidente con la variación registrada a nivel provincial. En el año 2008 la cantidad de explotaciones existentes en el departamento era de 185 , de las cuales el $41 \%$ corresponde a pequeños productores.

En este contexto, un grupo de pequeños productores de los departamentos Languiñeo y Tehuelches comenzaron a reunirse con el propósito de conformar un espacio colectivo donde canalizar problemáticas en común:

"Empezamos a movilizarnos algunos pequeños productores para ver qué alternativas podríamos encontrar de forma conjunta, agrupándonos, para que la realidad cambie" (primer presidente de la cooperativa).

"No habíamos encontrado nada que nos sostuviera y mucho menos que nos sacara a flote y nos perfilara en algo mejor, entonces bueno, vamos a buscarla juntos, con otros que son iguales que nosotros" (primer presidente de la Cooperativa).

La integración y el compromiso solidario entre productores fue progresivo, y el andar colectivo se sostenía por el objetivo común de hacer frente a la situación de vulnerabilidad en que se encontraban.

Quienes conformaron este espacio en sus inicios era un número reducido de pequeños productores que mantenían "relaciones interpersonales generadas en la misma zona de residencia o trabajo" (Lattuada \& Renold, 2004, p. 84), quienes exponían sus intereses y problemáticas en común. Como se trataba de un espacio con escaso grado de formalización institucional y estructuras internas poco desarrolladas, recurrieron a instituciones -tanto municipales, provinciales como nacionales- solicitando la posibilidad de acceder a instancias de capacitación vinculadas a la práctica del asociativismo. 
"Agrupados es la única forma". La experiencia solidaria y autónoma de la cooperativa Chacay Mamil por Natalia Luque, Hugo Bottaro y Graciela Preda

Desde el Programa Social Agropecuario (PSA) se propuso contactar un equipo de profesionales para brindar las capacitaciones correspondientes.

\begin{abstract}
"Hubo gente que se capacitó a través del área de Cooperativismo de la Provincia, por el año 2006. Trabajó con nosotros el PSA que ahora es la Secretaría de Agricultura, antes se llamaba PSA" (actual presidente de la Cooperativa).
\end{abstract}

"Vinieron tres personas a darnos una capacitación, un cursito, y ellos nos ayudaron, tres mujeres eran, nos ayudaron a la conformación del grupo. [...] lo más conveniente para nosotros era nuclearnos en una cooperativa, una cooperativa agropecuaria [...] ya que era ganadera, a baja escala, muy baja escala porque los productores que nucleaba la cooperativa tenían 200 animales, 150, 300, no sé, quién más tendría tenía 600 , y esos eran los rangos de bienes ganaderos" (primer presidente de la Cooperativa).

La conformación de la cooperativa Chacay Mamil se dio en ese accionar de manera conjunta en pos de logros comunes y guiados por "una racionalidad basada en valores, en este caso los aportados por los principios cooperativos de autoayuda, equidad, solidaridad, honestidad, transparencia, responsabilidad y vocación social" (Lattuada \& Renold, 2004, p. 83).

"Cuando se vende la lana cada socio cobra su parte que le corresponde y después seguimos andando, igual cuando se compran insumos cada socio aporta [...] Por ahí bueno, estamos en que somos bastante accesibles a que decimos: Fulano de tal no le alcanzó, no tiene y se lo cobramos para la otra cosecha de lana. Y así vamos como girando la rueda y tratando de ayudar a todos de alguna manera, en lo que podamos [...]" (productor asociado).

Su nombre hace alusión en lengua mapuche a rasgos característicos del territorio donde habitan los productores que la integran. El actual presidente refiere en su relato, que en el momento de la conformación la mayoría de los productores se encontraban en zona de Chacay, nombre que se adjudica a un arbusto típico de la región. Mientras que la palabra "Mamil", resulta de un error al momento de la registración del nombre, en realidad debía ser Mamuil que significa leña, "Leña de Chacay".

Una vez conformada la cooperativa se labra el Acta Constitutiva, "[...] tramitamos en el 2007, y la personería y toda la habilitación como Cooperativa 
nos Ilegó en el 2009" (primer presidente de la cooperativa, 2018); y en el mismo año en que se generó el Acta se eligió el presidente,

“El primer presidente se eligió a través de una asamblea [...] era como un líder que llevaba el grupo adelante" (productor asociado).

En el acta constitutiva de la cooperativa se detallan cuáles eran sus objetivos: “a) vender la producción de sus asociados, b) adquirir por cuenta de la cooperativa y proveer a los asociados, sus familias y el personal en general, o adquirir por cuenta de los mismos artículos de consumo, productos, instrumentos, maquinarias, entre otros, c) alquilar y arrendar infraestructura, d) adquirir y/o arrendar campos, chacras, granjas, u otros con destino a actividades agropecuarias, e) desarrollar actividades vinculadas a la agricultura, ganadería y toda producción animal en condiciones de desarrollar, f) siembras en general, cultivos bajo cubierta o huertas al aire libre, plantines forestales y forestación, g) cría de ganado y su comercialización, h) desarrollar actividades frutihortícolas, i) construcción, refacción y mantenimiento de instalaciones rurales en general y de las viviendas particulares de los asociados, j) conceder adelantos en dinero en efectivo a los asociados a cuenta de productos entregados o sobre la producción a entregar, k) dedicarse al estudio y defensa de los intereses económicos agropecuarios en general y de los asociados en particular, I) desarrollar actividades artesanales y comerciales de los productos que se obtengan, II) gestionar ante los Organismos Nacionales, Provinciales y Comunales las acciones que se crean necesarias, m) promover la capacitación permanente de los asociados en temas relacionados a lo productivo y asociativo, n) promover el trabajo asociativo y solidario entre los asociados; fomentar el espíritu de solidaridad y ayuda mutua entre los asociados y cumplir con el fin de crear una conciencia cooperativa" 5

Del análisis de los objetivos, se puede interpretar que la manera que imaginaron para permanecer en su condición de productores y aumentar sus ingresos, era mejorar la comercialización y eficientizar la producción, siendo la figura de cooperativa la que les permitía desarrollarlas. Se visualiza además gran "coherencia entre las prácticas y las normas originales [del cooperativismo]" (Lattuada \& Renold, 2004, p. 81), que como bien dicen los autores son propias de una forma de organización relativamente pequeña, local, con escasa burocratización interna y alta participación y compromiso de sus socios.

"Nosotros ahora lo que tenemos es una reunión mensual que es el primer sábado de cada mes, eso nos ha ayudado muchísimo, incluso se ha formado una especie de familia, la segunda familia es la cooperativa. Porque ahí tratamos temas importantes, se toman decisiones mediante votación y de paso

5 Extraído del Estatuto de la Cooperativa Agropecuaria Chacay Mamil Ltda. Capitulo I. Constitución, Domicilio, Duración y Objeto. Artículo $5^{\circ}$. 
"Agrupados es la única forma". La experiencia solidaria y autónoma de la cooperativa Chacay Mamil por Natalia Luque, Hugo Bottaro y Graciela Preda

compartimos siempre algo. Ahora cada vez viene más gente [...] Empezamos casi siempre a las 9 de la mañana y a veces son las 6 de la tarde y todavía estamos discutiendo algún tema, porque es el momento de hacer las preguntas, de hacer las consultas, propuestas, quejas, todo" (actual presidente de la Cooperativa).

El liderazgo ejercido por el primer presidente fue relevante al momento de gestarse la cooperativa, basado en un fuerte sentido de pertenencia e identidad con el territorio y el sector, a pesar que ya no estaba a cargo del manejo del campo familiar. Su historia no era ajena a la realidad de muchos pequeños productores, quienes "viven en condiciones de marginalidad o con muy pocas oportunidades de desarrollo social y productivo" (Sili \& Li, 2013, p. 59). Esta situación movilizó el interés por desarrollar un modelo de cooperación fundado en el espíritu colectivo y que promueva la permanencia del sector:

"Prácticamente me crié en el campo, en esos campos, en los de mi papá, en los de mi mamá... Bueno, hoy lo de mi mamá es una sucesión que administra un hermano. Viste que las familias antiguas eran familias grandes, lo de mi papá también era una sucesión, bueno mi papá después sacó sus partes, las vendió todas, pero bueno siempre el sentimiento por el campo siempre quedó" (primer presidente de la Cooperativa).

Las palabras de un técnico agropecuario que estuvo vinculado desde el inicio, son muy ilustrativa acerca de las convicciones del primer presidente en cuanto a la conformación de ese espacio colectivo:

“Él era así, iba para adelante, el 'no' no lo tenía en su cabeza. Y también iba para adelante porque sabía que los otros lo iban a apoyar, digamos, sí para beneficio más bien de todos, [...] si bien su familia tenía campo, él no era productor directo" (técnico agropecuario).

Cuando se conformó la cooperativa eran doce socios, quienes establecieron como requisito para asociarse acreditar la condición de pequeño productor ${ }^{6}$. La misma estaba dada por una cantidad máxima de animales.

"Lo que decidieron los que son socios fundadores era de que se consideraba como pequeño productor tener menos de 1000 ovinos o menos de 100 vacas, todo productor que esté en todo ese rango entraba a la cooperativa, podía acercarse a la

6 Cabe señalar que si bien quien ejercía la presidencia en ese momento no cumplía íntegramente ese requisito, en su elección primó la capacidad de gestión y liderazgo que detentaba. 
cooperativa. No quedó explícito en el estatuto, pero sí fue una decisión de ellos" (actual presidente de la Cooperativa).

En la actualidad son treinta y cinco los asociados, pertenecientes a localidades y parajes del departamento de Languiñeo y principalmente de Tehuelches: comprende los parajes rurales Sierra de Tecka, El Molle, Arroyo Seco y Las Mulas, también la comunidad mapuche Pocitos de Quichaura y las localidades de Río Pico y José de San Martín.

Cuando se indaga acerca de los motivos que impulsaron la conformación de una cooperativa, surgió la fuerte convicción de agruparse por la necesidad: "era momento de juntarnos", "empezamos a juntarnos para tener charlas".

"La situación que habíamos venido trayendo toda la vida hasta ese momento, con los campos muy chicos, en algunos lugares la tierra estaba en situación irregular, la lana prácticamente se vendía muy mal... digo la lana porque es el producto que más o menos sostiene al pequeño productor, la mayoría lamentablemente tenía empeñado el lote de lana, así que no dejaban ningún beneficio, no era algo que soportara los costos después del año; la venta de animales viejos... y bueno, entre todas esas cosas la situación empezaba a ser apremiante [...] hubieron zonas acá en la provincia de Chubut donde el pequeño productor prácticamente desapareció, terminó vendiendo, alquilando" (primer presidente de la Cooperativa).

Los involucrados en el proceso destacan que se trató de un periodo en el cual "se dieron a conocer alternativas un tanto prometedoras [...]. Ayuda para los pequeños productores, políticas de acompañamiento, seguimiento técnico" (primer presidente de la Cooperativa). Consideraban que era necesario gestionar las políticas públicas en forma organizada, dado que de otra manera era difícil acceder a créditos y/o programas de financiamiento. Es así que se acordaron espacios de encuentro, en una escuela o domicilio particular, para organizarse y establecer intereses en común. El testimonio de un técnico que acompañó ese proceso ilustra sobre esa etapa:

"Era un momento en el cual había muchos proyectos dando
vueltas, entonces más de uno cerraba. Tenías una organización
bien, funcionando, caía, podías escribir algo y lo mandabas, a
veces salía, a veces no, pero había plata" (Técnico Agropecuario).

La ganadería ovina es la producción por excelencia de estos pequeños productores, que comercializaron históricamente la lana y los corderos de forma individual; situación que comenzó a revertirse cuando observaron que a través de 
"Agrupados es la única forma". La experiencia solidaria y autónoma de la cooperativa Chacay Mamil por Natalia Luque, Hugo Bottaro y Graciela Preda

la organización y el asociativismo podrían mejorar sus condiciones de producción y comercialización.

"Estamos convencidos que agrupados es la única forma que tenemos los productores de salir adelante, lograr cosas, incluso lograr financiamiento porque individualmente es muy difícil, y lo saben los productores, y por eso nosotros seguimos luchando como cooperativa" (actual presidente de la cooperativa).

De todos modos, hay una diversidad de actividades que actualmente desarrollan los miembros de la cooperativa. Como bien lo explicitan Lattuada y Renold (2004), las organizaciones están marcadas por las transformaciones del contexto macroeconómico, las cuales exigen cambios en las mismas para su mejor desarrollo económico-empresarial.

"Actualmente somos 35 socios de la cooperativa, la mayoría son productores ovinos, después hay productores que tienen bovinos, caprinos que son los menos, pero tenemos. También dentro de la cooperativa tenemos artesanos, productores de cerdos, que eso es una producción que está surgiendo ahora [...] después productores de aves, tenemos agricultores [...]" (presidente de la cooperativa).

"Nos iniciamos en aquel momento para poder vender los productos que hacíamos en conjunto, para sacarle más beneficios, para eso se armó la cooperativa" (productor asociado).

"El objetivo principal era vender y trabajar en conjunto" (productor asociado).

El técnico que los asesoró en el inicio relata que otros productores que no pertenecían a la cooperativa empezaron a ver que sus condiciones eran similares y que el trabajo organizado era positivo, y así paulatinamente se fueron sumando.

\section{Construyendo la acción colectiva}

En las primeras experiencias compartidas, durante los años 2002/2003, se hicieron compras conjuntas de pasto, leña, fardos y se aspiraba a vender la lana de la misma forma, pero tuvieron algunas complicaciones en el proceso que finalmente repercutió en la estabilidad del grupo. Estos problemas vinculados a la comercialización de la lana se superaron una vez constituidos como cooperativa, 
de acuerdo a lo mencionado en una jornada de pequeños productores que tuvo lugar en el año $2017^{7}$ :

“Hoysíse puede decir que se vende la lana mediante licitación, ya llevamos cuatro licitaciones logradas; acá a las oficinas nuestras vinieron los compradores de lana a presentar sus ofertas, esta vez de seis que hay en la zona estuvieron cuatro, y uno pidió la oportunidad de aportar por teléfono. Se vendió muy bien el lote de lana, este año se lograron juntar 30.000 kilos, en la zafra anterior 25.000, en la zafra anterior 16.500, y la primera vez que se había juntado la lana para empezar a vender eran 8.000 y pico de kilos, es decir que hubo un progreso" (actual presidente de la cooperativa).

\begin{abstract}
"Las ventas de lana han llevado mucho tiempo porque eran varias reuniones de coordinar un montón de cosas, arrancaba con el curso de lana, que daban con Prolana, y después de eso armar todos los lotes hasta llegar a la venta, y eso eran acuerdos y acuerdos, el que decía que iba a entrar a la venta no podía vender por afuera" (técnico agropecuario).
\end{abstract}

Poder consolidarse en la venta conjunta de lana fue un proceso paulatino, pero una vez establecido modificó la relación entre los actores del territorio, dándole mayor peso al sector de los pequeños ganaderos.

"Con la venta conjunta le jorobamos el negocio a varios, porque ya no le compraron al precio que querían, sino que ellos le ponían el precio y sino no te la vendían [...] con el laburo que venían haciendo del campo más otras cosas que ellos ponían de afuera, les permitía, los pocos fardos que tuvieran, guardarlos, aguantarlos y venderlos cuando ellos querían, un año por lo menos" (técnico agropecuario).

El canal de comercialización tradicional de la lana para los pequeños productores de la zona eran los llamados mercachifles o bolicheros. Actores que "no sólo fueron importantes como intermediarios entre los pequeños y medianos productores y los consignatarios de lanas en los mercados centrales, sino que también eran despensa, almacén de ramos generales, ferretería, bar y albergue, y, con el tiempo, hasta acreedores" (Ejarque, 2014, p. 94).

Una vez formalizada la cooperativa, se comenzaron a establecer criterios en común en lo que respecta a determinadas prácticas productivas y comerciales,

$73^{\circ}$ Jornadas Regionales Ovinas para pequeños productores - jueves 7 de septiembre de 2017 en la calle Estrada 850, de la localidad de Gobernador Costa. 
"Agrupados es la única forma". La experiencia solidaria y autónoma de la cooperativa Chacay Mamil por Natalia Luque, Hugo Bottaro y Graciela Preda

brindando una imagen consolidada, no solamente hacia el interior del sector de los pequeños productores sino también hacia afuera.

"Si uno no intenta hacer las cosas no va a saber si es así o no,
por eso hemos tenido problemas, pero los hemos resuelto para
seguir adelante porque estamos convencidos que agrupados es
la única forma" (actual presidente de la Cooperativa).

Otra de las actividades en las cuales incursionaron, fue en la práctica del engorde de ovinos realizado en el establecimiento de uno de los miembros de la cooperativa,

\begin{abstract}
"Se ha hecho engorde en conjunto, comenzamos a hacer en el 2011 [...] éramos cinco, pero quedamos cuatro, 131 animales, una duración promedio de 60 días. Ese año nos fue muy bien porque recién se empezaron a hacer los engordes, cuando los fuimos a vender se vendían a muy buen precio, compraron todo de una. Al año siguiente ya éramos más productores, éramos siete, ese año tuvimos 193 animales, llegamos en 75 días" (actual presidente de la cooperativa).
\end{abstract}

Esta experiencia involucró al dueño del establecimiento, a técnicos de organismos públicos que brindaron asesoramiento, a productores y a estudiantes de la escuela secundaria -con orientación agropecuaria- de Gobernador Costa (con quien la cooperativa suscribió un convenio); también se contrató a una persona para repartir alimento y realizar el control.

Así mismo, vinculado a la producción de carne, se realizó la búsqueda de nuevos nichos comerciales para la ubicación de los productos, para lo cual se generó una feria anual y venta a carnicerías locales. Desde el año 2014 se realiza la feria anual agrícola ganadera.
"Ahí cada productor lleva lo que tiene, digamos hay venta de corderos en pie y después van a faena ahíal matadero municipal, después hay venta de asado. Y ahí está en venta cordero, asado de potro, chivo [...] Después bueno, hay otros productores que tienen gallinas, por ejemplo, la mami ella suele traer huevos, pan dulce, torta fritas, esa es su venta" (productor asociado).

Este evento tiene lugar en el mes de diciembre, generalmente se realiza durante el fin de semana y es un espacio de encuentro entre diversos productores donde acude gran cantidad de público en general. Sus orígenes están vinculados con el estatuto, ya que en el Artículo $5^{\circ}$ del Capítulo 1 se menciona como objetivo la posibilidad de "vender la producción de sus asociados, pudiendo efectuar remates o ferias [...]". 
"Lo único que estábamos haciendo era vender lana mediante licitación y era todo, o por ahí un engorde y vendíamos finalizado. Así que empezamos a hacer la feria... para la cual tuvimos mucha colaboración del INTA. [...] Lo logramos hacer, quedamos contentos" (actual presidente de la cooperativa).

Diversos fueron los espacios y los vínculos que se gestaron durante el transcurso de los años.

"La cooperativa compró al Municipio local dos hectáreas, [...] tiene un galpón de acopio que fue financiado por PRODERPA" (actual presidente de la cooperativa).

También se realizaron mejoras prediales que permitieron mejorar la calidad de la producción y de la vida de algunos de sus miembros.

"Se consiguió a través de Ley Ovina cinco perforaciones completas [...] un tanque de 10.000 litros para acumulación de agua. Se deriva el agua a las casas y después tienen bebederos cada productor para los animales" (actual presidente de la Cooperativa).

En las actividades mencionadas, como en tantas otras, intervinieron organismos del estado municipal, provincial y nacional. Situación que así relata el técnico asesor:

"La cooperativa se empezó a hacer muy visible, y ya no era la cooperativa que laburaba con los técnicos, sino que ya venían de Provincia a buscarlos para ofrecerles cosas, para invitarlos. [...] siempre les planteamos que la idea no fuera una cooperativa fuerte y los productores ahí recibiendo, sino que si crecen los productores que crezca la cooperativa, no al revés que crezca la cooperativa como si fuera una empresa, entonces con esa visión creo que tuvieron un cambio tremendo" (técnico agropecuario).

En el relato acerca de la trayectoria de la cooperativa, es posible observar que en el andar conjunto han adquirido un nivel de organización sólida y consolidada, en el que fueron tomando decisiones y realizando acciones en respuesta a los contextos cambiantes. Este caso de estudio muestra que las estrategias colectivas se comprenden en relación al espacio social donde se realizan, y reconocer las capacidades de los agentes en la resolución de los problemas que se les presentan habilita a pensar "la organización social como una forma de continua creación" (Coulon citado en Giarraca, 2017, p. 202). 
"Agrupados es la única forma". La experiencia solidaria y autónoma de la cooperativa Chacay Mamil por Natalia Luque, Hugo Bottaro y Graciela Preda

\section{Conclusiones}

El estudio de la conformación y trayectoria de la cooperativa Chacay Mamil permite observar cómo un grupo de pequeños ganaderos del centro oeste de la provincia de Chubut buscó permanecer en el espacio productivo a través de una estrategia colectiva y solidaria. Tiene como particularidad distintiva que se sitúa en una provincia con pocos antecedentes de cooperativas agrarias con trayectoria prolongada, y en una región tradicionalmente identificada con las medianas y grandes unidades, donde los pequeños productores han tenido escaso o nulo reconocimiento. Tal es así, que las formas organizativas en torno a la pequeña producción han sido prácticamente inexistentes.

La puesta en práctica de los valores cooperativos les permitió dar respuesta a necesidades históricas de sus asociados. En el análisis de la trayectoria se observa un proceso que se fue consolidando y complejizando, atendiendo en una primera etapa aspectos vinculados a la comercialización, para avanzar luego en experiencias de producción conjunta, gestión y ejecución de proyectos productivos, manejo de fondos de microcrédito y la representación gremial ante organismos provinciales.

Este fortalecimiento hizo posible vinculación con los distintos actores del territorio desde una posición autónoma. Por un lado, las que se establecieron entre los propios asociados-grupo que se fue ampliando paulatinamente-; y por el otro, con las demás organizaciones de productores existentes en la zona y con los espacios de encuentro, como las Mesas de Desarrollo Locales y Regionales.

El proceso de constitución y desarrollo de la Cooperativa se vio favorecido por la implementación de políticas públicas en apoyo a la agricultura familiar y por los vínculos que se establecieron con la Universidad de la Patagonia San Juan Bosco, la Subsecretaría de Agricultura Familiar y el INTA.

No puede desconocerse, que gran parte de ese período se caracterizó por buenos precios internacionales de la lana y un tipo de cambio que favoreció la producción de bienes exportables, estimulando el desarrollo de canales de comercialización asociativos.

Consideramos que los resultados de este estudio aportan elementos para analizar las estrategias de desarrollo rural en un territorio caracterizado por restricciones ambientales, productivas y socio-económicas. La conformación de la Chacay Mamil se dio en el marco de un proceso en el que se combinaron espacios de capacitación y diálogo de saberes, resignificando los caracteres identitarios, valorizando las experiencias previas, y muy especialmente incorporando competencias tanto en los aspectos productivos como de gestión. 


\section{Referencias bibliográficas}

Ministerio de Protección (s.f.). Acta Constitutiva de la Cooperativa Agropecuaria. Recuperado de http://www.mp.gba.gov.ar/cooperativas/downloads/Acta_ Constitutiva_y_Estatuto_Social_rurales_res750-94\%20INAC.pdf

Bandieri, S. (2005). Historia de la Patagonia. Buenos Aires: Sudamericana.

Barsky, O., \& Gelman, J. (2006). Historia del agro argentino. Desde la Conquista hasta fines del siglo XX. Buenos Aires: Grijalbo-Mondado.

Bourdieu, P. (1988). La Distinción. Criterios y bases sociales del gusto. Madrid: Taurus.

Bourdieu, P. (1991). El sentido práctico. Madrid: Taurus.

Bourdieu, P., Chamboredon, J. C., \& Passeron, J. C. (2002). El oficio de sociólogo. Presupuestos epistemológicos. Buenos Aires: Siglo Veintiuno.

Ejarque, M. (2014). La construcción social de los problemas ambientales en torno a la ganadería ovina de las tierras secas chubutenses: agentes sociales, sus interpretaciones y sus prácticas (Tesis Doctoral). Universidad de Buenos Aires:, Buenos Aires, Argentina.

Fernández, L. (2018). Políticas públicas para la agricultura familiar en Argentina durante el periodo 1990-2015. Nuevos y conocidos elementos en la agenda de debate. Trabajo y Sociedad, 30, 219-241.Recuperado de https://www. unse.edu.ar/trabajoysociedad/30\%20FERNANDEZ\%20LISANDRO\%20 Agricultura\%20familiar.pdf

Gaitán, J., Bran D., \& Azcona C. (2015). Tendencias del NDVI en el periodo 20002014 como indicador de la degradación de tierra en la Argentina: ventajas y limitaciones. Agriscientia, 32(2), 83-93.

Giarracca, N. (2017). Estudios rurales y movimientos sociales: miradas desde el Sur. Antología Esencial. Recuperado de https://www.clacso.org.ar/antologias/ detalle.php?id_libro=1317

Instituto Nacional de Estadisticas y Censos (INDEC). Censos Nacional Agropecuarios 2002. Recuperado de https://www.indec.gob.ar/indec/web/Nivel4Tema-3-8-87

Instituto Nacional de Estadísticas y Censos (INDEC). Censos Nacional Agropecuarios 2008. Recuperado de https://www.indec.gob.ar/indec/web/Nivel4Tema-3-8-87 
"Agrupados es la única forma". La experiencia solidaria y autónoma de la cooperativa Chacay Mamil por Natalia Luque, Hugo Bottaro y Graciela Preda

Lattuada, M., \& Renold, J. (2004). El cooperativismo agrario ante la globalización. Buenos Aires: Siglo veintiuno.

Li, S., \& Bottaro, H. (2010). Las mesas de desarrollo en el NO de Chubut. XV Jornadas Nacionales de Extensión Rural y VII del Mercosur, Potrero de los Funes. Jornadas llevadas a cabo en Argentina. Recuperado de http://www.aader.org.ar/XVI_jornada/trabajos/archivos/2012/011_trabajo_ atm_bottaro.pdf

Maggiori, E. (2003). Acá vamos a plantar un pueblo y se va a llamar Gobernador Costa: Historias del Valle del Genoa. Comodoro Rivadavia: Gráfica Andrade.

Maggiori, E. (2010). Tecka: una aproximación histórica. Comodoro Rivadavia: Pablo Ghione Editores.

Murgida, A., \& Gentile, E. (2014). Aceptabilidad y amplificación del riesgo en la estepa nor-patagónica. En J. Viand., \& F. Briones (comp). Riesgos del Sur. Diversidad de riesgos de desastres en Argentina. Red de Estudios Sociales en Prevención de Desastres en América Latina. https://www.desenredando.org/public/2015/riesgosalsurArgentina.pdf

Nogueira, M. E., Urcola, M., \& Lattuada, M. (2017). La gestión estatal del desarrollo rural y la agricultura familiar en Argentina: estilos de gestión y análisis de coyuntura 2004-2014 y 2015-2017. Revista Latinoamericana de Estudios Rurales, 2(4), 23-59.

Ressel, A, \& Silva, N. (2008). Estudio de las cooperativas agrarias en Argentina. En J. Martí (Coord.). Cooperativas e Integración Regional. La trayectoria de las cooperativas agropecuarias y de ahorro y crédito en el MERCOSUR, (pp. 74-109). Recuperado de https://idl-bnc-idrc.dspacedirect.org/bitstream/ handle/10625/35359/127339.pdf?sequence=1\&isAllowed=y

Hernandez Sampieri, R., Collado, C., \& Baptista, P. (2010). Metodología de la investigación. México: Mc Graw Hill/Interamericana. Recuperado de https://www.esup.edu.pe/descargas/dep_investigacion/Metodologia\%20 de\%20la\%20investigaci\%C3\%B3n\%205ta\%20Edici\%C3\%B3n.pdf

Sandoval Casillimas, C. (2002). Investigación cualitativa. Bogotá: ICFES.

Sili, M., \& Li, S. (2013). Las tierras fiscales en la Patagonia argentina: un viejo problema irresuelto. Huella, 16(9), 54-77. Recuperado de http://www.biblioteca.unlpam.edu.ar/publicaciones/pub-huellas.htm\#2012-16

Schwartz, H., \& Jacobs, J. (1984). Sociología cualitativa. Método para la construcción de la realidad. México: Trillas. 
Pensamiento y Acción Interdisciplinaria, Volumen 6, número 2, año 2020. ISSN 0719-8078. pp. 50-69

Dirección de correspondencia:

Natalia Luque

Contacto: luque.natalia@inta.gob.ar

(C) (3) Esta obra se encuentra bajo una Licencia de Creative Commons 